\title{
Suppression of left ventricular early diastolic filling by long axis asynchrony
}

\author{
Michael Y Henein, Derek G Gibson
}

Cardiac Department, Royal Brompton National Heart and Lung Hospital, London

M Y Henein

D G Gibson

Correspondence to: Dr Derek G Gibson, Cardiac Department, Royal Brompton National Heart and Lung Hospital, Sydney and Lung Hospital, Sydney

Accepted for publication 27 July 1994

\begin{abstract}
Objective-To assess how early diastolic transmitral flow is suppressed in a group of patients in whom effective ventricular filling occurred exclusively with atrial systole.

Design-Prospective examination of the left ventricular transverse and longitudinal axes and transmitral Doppler flow.

Setting-A tertiary referral centre for cardiac diseases.
\end{abstract}

Subjects-20 patients (mean (SD) age 65 (10) years) with isolated transmitral late diastolic flow were studied. None had sinus tachycardia, prolonged PR interval or a summation flow pattern. 21 normal individuals of similar age served as controls.

Results-The left ventricle was usually dilated, end diastolic diameter $(6.6(1 \cdot 0) v$ $4.9(0.5) \mathrm{cm}, P<0.001)$ and end systolic diameter $(5.4(1.1)$ v $3.3(0.5) \mathrm{cm}, P<$ 0.001 ) were both increased, and fractional shortening of the minor axis reduced $(16(7) \% v 30(10) \%, P<0.001)$ in patients in whom left ventricular early diastolic filling was absent compared with those of normal controls. Mitral valve opening was late after aortic valve closure $\left(A_{2}\right)$ (115 (30) v 60 (10) ms, P < $0 \cdot 001)$. The minor axis increased during this period $(30(20) \%$ v $8.6(2.5) \%, P<$ $0 \cdot 001)$. Onset of detectable transmitral flow was further delayed after cusp separation (85 (25) $v 25$ (10) $\mathrm{ms}, P<0.001$ ). Left ventricular long axis function was very abnormal. Onset of shortening was delayed with respect to the $q$ wave at the left and septal sites (150 (40) $v 90$ (20) ms and 145 (30) $v 80(10) \mathrm{ms}$ respectively, $P$ $<0.001)$ and major shortening occurred after, rather than before, $A_{2}(25$ (12) $v$ $-10(2.5) \%$ and $50(30) v-6.6(0.3) \%$ total excursion, $P<0.001)$. Although the long axis lengthened a little at the start of early diastole, its dominant component occurred in late diastole to coincide with atrial systole. The relative $A$ wave was thus greatly increased at both sites (67 (17) $v 29$ (6)\% and 77 (13) $v 33(8) \%, P<$ 0.001).

Conclusion-Prolonged left ventricular long axis shortening and delayed onset of lengthening effectively suppress early diastolic transmitral flow even though the minor axis increases and mitral cusps separate apparently normally. This grossly asynchronous left ventricular relaxation may interfere with filling by dissipating normal ventricular restoring forces.

\section{(Br Heart f 1995;73:151-157)}

Keywords: left ventricular diastolic function, long axis asynchrony.

In early diastole, left atrial pressure, ventricular relaxation and restoring forces interact on the atrioventricular pressure gradient that determines transmitral flow. ${ }^{1}$ It is difficult to isolate the effects of these different factors in intact humans, not only because they mutually interact, but because they all are profoundly modified by ventricular filling. Temporarily occluding the mitral valve orifice in experimental animals has proved helpful in eliminating filling and separating the effects of relaxation from those of restoring forces. ${ }^{2}$ Similar information has been obtained in a less controlled way in humans during balloon dilatation of the mitral valve. ${ }^{3}$ In the present study we investigated a group of patients in whom a discrete early diastolic transmitral flow-velocity peak was undetectable. In doing so, we hoped to find out why the $\mathrm{E}$ wave was effectively suppressed in these patients. We also wished to take advantage of this unusual state of affairs to see how other early diastolic events are affected when blood does not flow into the ventricle.

\section{Patients and methods}

PATIENTS

Consecutive patients were identified in whom there was no identifiable early diastolic peak on the pulsed Doppler record of transmitral flow. Patients with tachycardia of more than $100 \mathrm{beats} / \mathrm{min}$ were excluded, as were those with a summation filling pattern. ${ }^{4}$ All patients were in sinus rhythm, and left ventricular filling occurred after the $P$ wave of the electrocardiogram during atrial systole. There were 20 patients (15 male) of mean (SD) age 65 (10) years. Four patients had a history of myocardial infarction and two had coronary artery bypass grafts. Dilated cardiomyopathy was echocardiographically confirmed in three patients and in four a history of shortness of breath was the main referring symptom; one had unstable angina and severe triple vessel disease. Three patients had a history of cerebral transient ischaemic attacks but no other evidence of cardiac disease. The remaining four patients had individual diagnoses of left 
ventricular aneurysm, coarctation of the aorta, aortic stenosis and aortic valve replacement with a Björk-Shiley prosthesis. Thirteen patients had abnormal electrical conduction, five with classical left, five right bundle branch block and three with intraventricular conduction defect. The PR interval was within the upper limit of the normal $95 \%$ confidence interval $(220 \mathrm{~ms})$ in all patients. All patients were receiving a diuretic agent and all except two were taking an angiotensin converting enzyme (ACE) inhibitor.

We also investigated 21 healthy controls (mean (SD) age 58 (11) years, 14 males). None had a history of heart disease, hypertension, diabetes, or electrocardiographic evidence of conduction abnormality.

\section{METHODS}

In patients and controls mitral Doppler velocities were obtained using pulsed Doppler $2 \cdot 5$ $\mathrm{MHz}$ transducer interfaced to a HewlettPackard model 77020 A Sonos 1000 echocardiograph (Andover, USA). Recordings were taken from the apical four chamber view with the sample volume at the tips of the mitral valve leaflets. A filter of $250 \mathrm{~Hz}$ was used. Two dimensional guided echocardiographic studies were undertaken using the same equipment. $M$ mode recordings of the left ventricular minor axis were obtained, from the parasternal long axis view, with the cursor by the tips of the mitral valve leaflets while the patient was in a semi-lateral position. We also recorded $M$ mode echocardiograms of the left and right ventricular long axes from the apical four chamber view while the cursor was at the left, septal and right angles of the atrioventricular rings respectively. An electrocardiogram and phonocardiogram were superimposed on all traces which were recorded at a paper speed of $100 \mathrm{~mm} / \mathrm{s}$. All $\mathrm{M}$ mode records were digitised. ${ }^{5}$ Twelve lead electrocardiograms were recorded with a Hewlett-Packard electrocardiograph. PR interval and QRS duration were determined by built in software.
Table 1 Comparison of mitral doppler and minor axis mean (SD) measurements between normal controls and patients in whom left ventricular early diastolic filling is absent

\begin{tabular}{|c|c|c|}
\hline Variable & $\begin{array}{l}\text { Normal controls } \\
(n=21)\end{array}$ & $\begin{array}{l}\text { Patients without lefi } \\
\text { ventricular early } \\
\text { diastolic filling } \\
(n=20)\end{array}$ \\
\hline \multicolumn{3}{|l|}{ Mitral doppler } \\
\hline E wave velocity $(\mathrm{m} / \mathrm{s})$ & $0.7(0 \cdot 1)$ & - \\
\hline A wave velocity $(\mathrm{m} / \mathrm{s})$ & $0.5(0 \cdot 1)$ & $1.03(0 \cdot 2)^{\star \star}$ \\
\hline E/A ratio & $1.4(0.4)$ & - \\
\hline $\mathrm{RR}$ interval (ms) & $790(160)$ & $710(60)$ \\
\hline $\mathrm{A}_{2}$ to mitral cusp separation (ms) & $60(10)$ & $115(30)^{\star \star}$ \\
\hline Cusp separation to onset of flow (ms) & $25(10)$ & $85(25)^{\star \star}$ \\
\hline \multicolumn{3}{|l|}{ Minor axis } \\
\hline End diastolic diameter $(\mathrm{cm})$ & $4.9(0.5)$ & $6 \cdot 6(1 \cdot 0)^{\star \star}$ \\
\hline End systolic diameter $(\mathrm{cm})$ & $3.3(0.5)$ & $5 \cdot 4(1 \cdot 1)^{\star \star}$ \\
\hline Fractional shortening (\%) & $30(10)$ & $16(7)^{\star \star}$ \\
\hline Peak shortening rate $(\mathrm{cm} / \mathrm{s})$ & $9 \cdot 0(3 \cdot 0)$ & $4 \cdot 8(2 \cdot 1)^{\star \star}$ \\
\hline Peak lengthening rate $(\mathrm{cm} / \mathrm{s})$ & $10 \cdot 4(2 \cdot 6)$ & $6 \cdot 1(4 \cdot 0)^{\star \star}$ \\
\hline \multicolumn{3}{|l|}{ Posterior wall } \\
\hline Peak rate of posterior wall lengthening $(\mathrm{cm} / \mathrm{s})$ & $12(4)$ & $4 \cdot 3(2 \cdot 6)^{\star \star}$ \\
\hline$A_{2}$ to peak rate of posterior wall lengthening $(\mathrm{ms})$ & $95(15)$ & $76(20)^{\star}$ \\
\hline $\mathrm{A}_{2}$ to end of posterior wall lengthening (ms) & $130(20)$ & $95(30)^{\star \star}$ \\
\hline
\end{tabular}

\section{MEASUREMENTS}

Transmitral Doppler: we measured peak A wave velocity and the time interval from aortic valve closure $\left(A_{2}\right)$ and from mitral cusp separation to the onset of the $A$ wave.

Minor axis: left ventricular end diastolic and end systolic diameters were measured at the onset of the $q$ wave of the electrocardiogram (end diastole) and $A_{2}$ of the phonocardiogram (end ejection), respectively. $A_{2}$ was identified as the first high frequency vibration of the aortic component of the second heart sound and confirmed from the aortic echogram. Fractional shortening was calculated as the systolic decrease in left ventricular minor axis divided by end diastolic diameter. Peak rates of minor axis shortening and lengthening and posterior wall thinning were determined from the digitised traces. We also measured the time interval from $A_{2}$ to the peak rate of posterior wall thinning and the extent of any dimension change during the two intervals between $A_{2}$ and mitral cusp separation and between $A_{2}$ and onset of transmitral flow. These were expressed as a percentage of the total increase in the cardiac cycle.

Long axis: we measured overall long axis excursion at the three sites-that is, left, septum, and right from maximum shortening to maximum lengthening. ${ }^{6}$ Systolic shortening was taken as the displacement from the onset of shortening after the $q$ wave to the time of $A_{2}$. Further shortening frequently occurred after $\mathrm{A}_{2}$ and its extent was also measured. Finally the extent of lengthening during atrial systole was assessed. Two time intervals were measured:

(a) from q of the electrocardiogram to the onset of long axis shortening;

(b) from $\mathrm{A}_{2}$ of the phonocardiogram to the onset of lengthening. From the digitised traces we measured the peak rates of systolic shortening and early diastolic lengthening. Any dimension change before mitral cusp separation was expressed as a percentage of the total excursion during cardiac cycle. Peak rates of dimension change before mitral cusp separation and during atrial systole were also measured.

\section{STATISTICAL ANALYSIS}

Values are presented as mean (SD). Patients in whom left ventricular early diastolic filling was absent were considered as one homogenous group and compared with normal controls using the unpaired $t$ test. $\mathrm{P}<0.05$ was considered significant.

\section{Results}

MITRAL DOPPLER

Velocity of the isolated A wave in the mitral Doppler record in patients in whom left ventricular early diastolic filling was absent was significantly greater than in normal controls (table 1).

\section{MINOR AXIS}

The PR interval was not significantly different between patients and normal controls (table 
Figure 1 (A) Recordings from a normal control. Upper panel: left ventricular minor axis at the level of the mitral cusps. Middle panel: transmitral Doppler flow. Lower panel: long axis recording of the left site of the mitral ring. The records are aligned on $A_{2}$. (B) Similar recordings from a patient in whom left ventricular early diastolic filling was absent. Note the delay in mitral cusp separation (vertical dotted line) with respect to $A 2$ on the phonocardiogram (vertical continuous line) and the further delay between mitral cusp separation and the onset of transmitral flow. PCG, phonocardiogram; $E C G$, electrocardiogram; $A 2$, aortic valve closure.

(Depth scale $=1 \mathrm{~cm}$ or 20 $\mathrm{cm} / \mathrm{s}$ ).

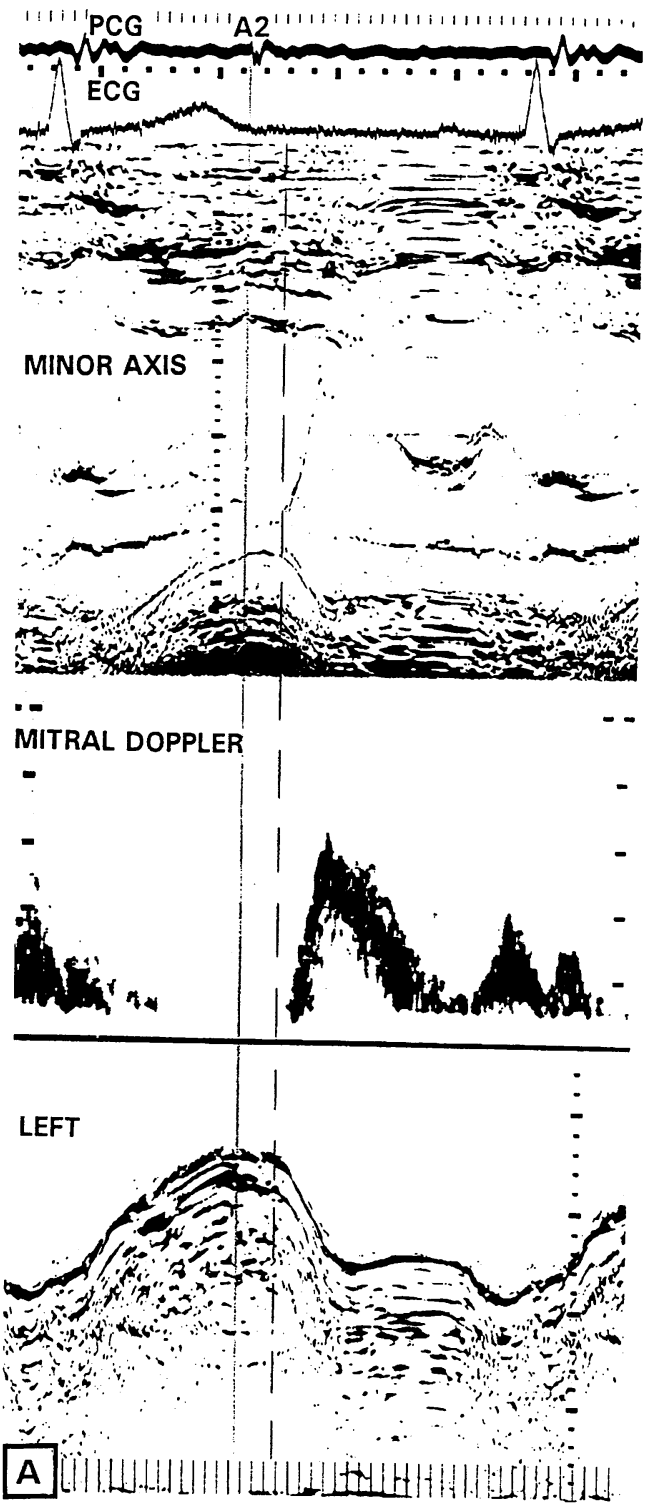

1). Left ventricular end diastolic and end systolic diameters were both increased and fractional shortening reduced (fig 1). The peak systolic shortening rate was reduced as was the peak early diastolic lengthening rate. The peak thinning rate of the posterior wall was also reduced.

Table 2 Comparison of systolic long axis function mean (SD) measurements between normal controls and patients in whom left ventricular early diastolic filling is absent

\begin{tabular}{lll}
\hline & $\begin{array}{l}\text { Normal controls } \\
(n=21)\end{array}$ & $\begin{array}{l}\text { Patients without left } \\
\text { ventricular early } \\
\text { diastolic filling } \\
(n=20)\end{array}$ \\
Variable & $1 \cdot 1(0 \cdot 2)$ & $0 \cdot 39(0 \cdot 37)^{\star \star}$ \\
\hline $\begin{array}{l}\text { Systolic excursion (cm) } \\
\text { Left }\end{array}$ & $1 \cdot 05(0 \cdot 2)$ & $0 \cdot 19(0 \cdot 12)^{\star \star}$ \\
Septum & $1 \cdot 7(0 \cdot 25)$ & $0 \cdot 75(0 \cdot 4)^{\star \star}$ \\
Right & $90(20)$ & $150(40)^{\star \star}$ \\
Q to onset of shortening (ms) & $80(10)$ & $145(30)^{\star \star}$ \\
Left & $80(10)$ & $110(30)^{\star \star}$ \\
Septum & & $4 \cdot 6(1 \cdot 9)^{\star \star}$ \\
Right & $8(1 \cdot 5)$ & $3 \cdot 2(1 \cdot 1)^{\star \star}$ \\
Peak shortening rate (cm/s) & $7 \cdot 5(1 \cdot 2)$ & $8 \cdot 9(2 \cdot 3)$ \\
Left & $10(2 \cdot 0)$ & \\
Septum & & \\
Right & & \\
\hline
\end{tabular}

${ }^{\star} \mathrm{P}<0.01 ;{ }^{\star \star} \mathrm{P}<0.001 v$ normal

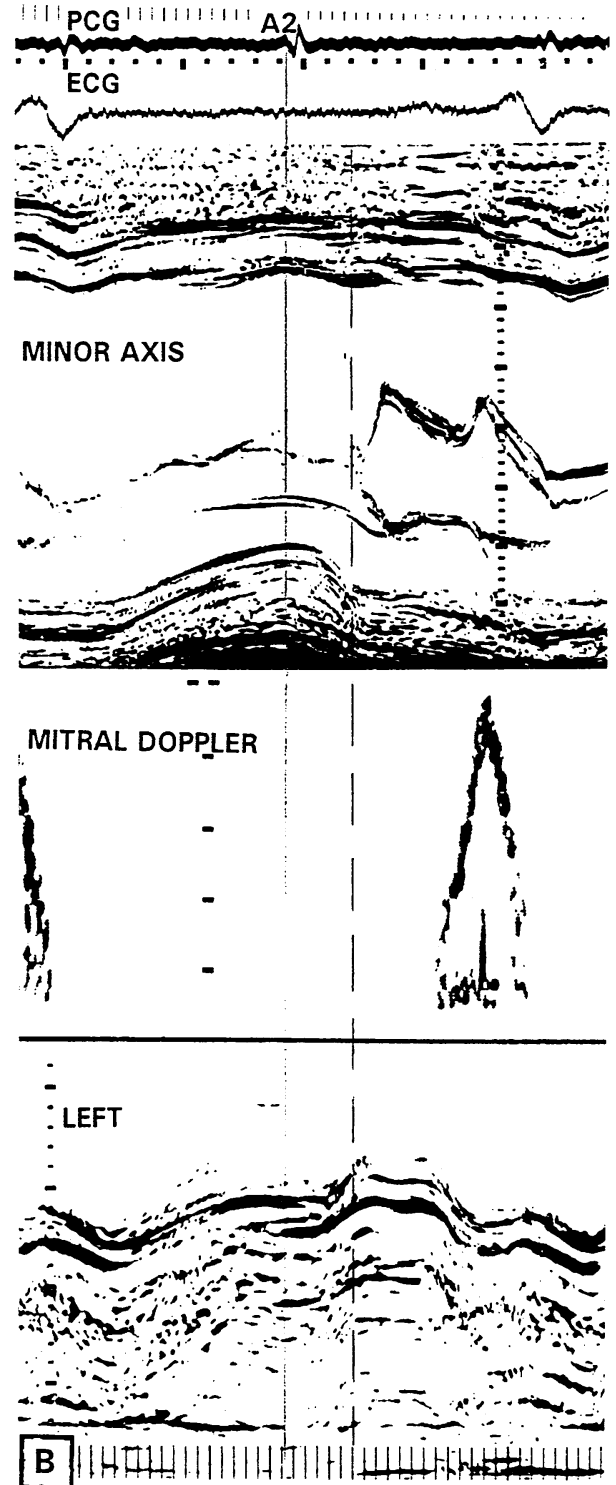

LONG AXIS

The overall amplitude of long axis excursion was reduced at both left and right ventricular sites (table 2). Systolic long axis function was disturbed: the extent of systolic shortening was reduced and its onset delayed with respect to the $\mathrm{q}$ wave of the electrocardiogram (fig 2, table 2). The peak shortening rate was low. Diastolic function was particularly abnormal: following $\mathrm{A}_{2}$ and before mitral cusp separation there was further abnormal shortening with high velocity (tables 3 and 4 ). This shortening persisted after the mitral cusps separated until the onset of transmitral blood flow with atrial systole. The extent of long axis lengthening during atrial systole was increased at both left ventricular sites; peak lengthening velocity was also increased at the septum (table 5).

INTERRELATION OF MINOR AXIS, LONG AXIS AND MITRAL DOPPLER FLOW

We took the time of $A_{2}$ as the onset of diastole. Minor axis posterior wall thinning in normal controls ends $130 \mathrm{~ms}$ after $\mathrm{A}_{2}$ to coincide with the peak of the mitral $\mathrm{E}$ wave (table 
Figure 2 (A) Long axis recordings from the left and septal left ventricular sites taken from a normal control. (B) Long axis recordings of the same sites taken from a patient in whom left ventricular early diastolic filling was absent. Note the delayed onset of shortening (dotted line) with respect to the $q$ wave of the ECG and the abnormal shortening after $\mathrm{A}_{2}$ during early diastole. $P C G$, phonocardiogram; ECG, electrocardiogram $A 2$, aortic valve closure.

Figure 3 Demonstration of the interrelation between mitral Doppler flow and left ventricular minor and long axes aligned on $A 2$. (A) Recordings from a normal control. (B)

Recordings from a patient in whom left ventricular early diastolic filling was absent. Note the early lengthening of the minor axis posterior wall. Peak early diastolic thinning (dotted line) has ended significantly before mitral cusp separation

(continuous line). Mitral cusp separation itself coincides with peak long axis shortening. The onset of flow coincides with that of late diastolic long axis lengthening (arrow) and follows mitral cusp separation by

approximately $100 \mathrm{~ms}$. ECG, electrocardiogram; $P C G$, phonocardiogram; $A 2$, aortic valve closure; MCS, mitral cusp separation.

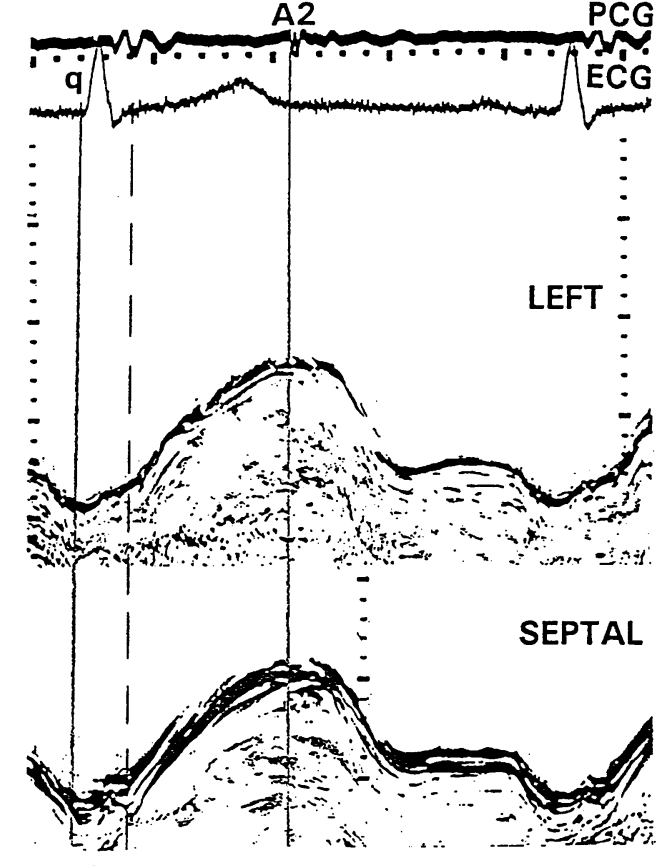

A

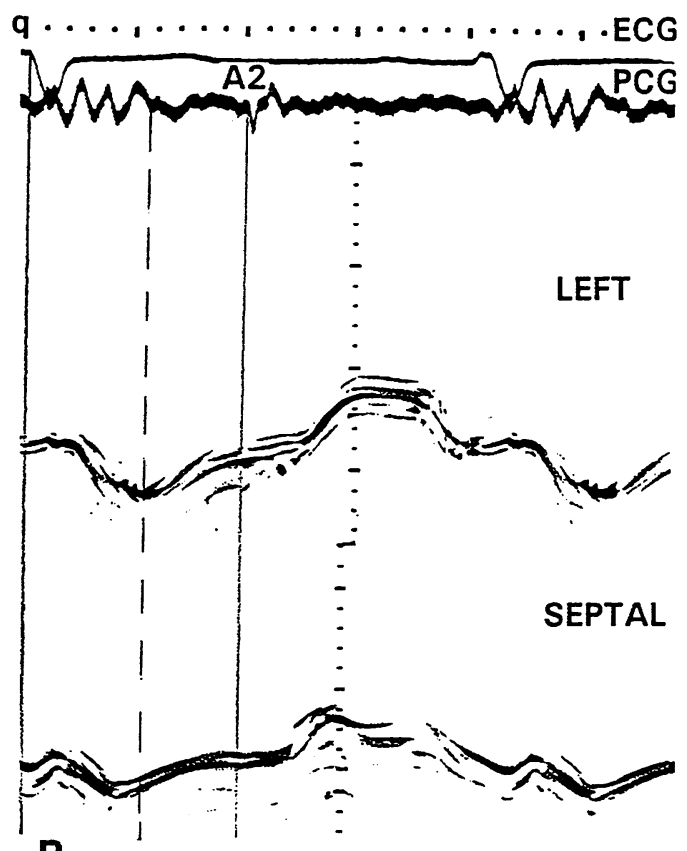

B

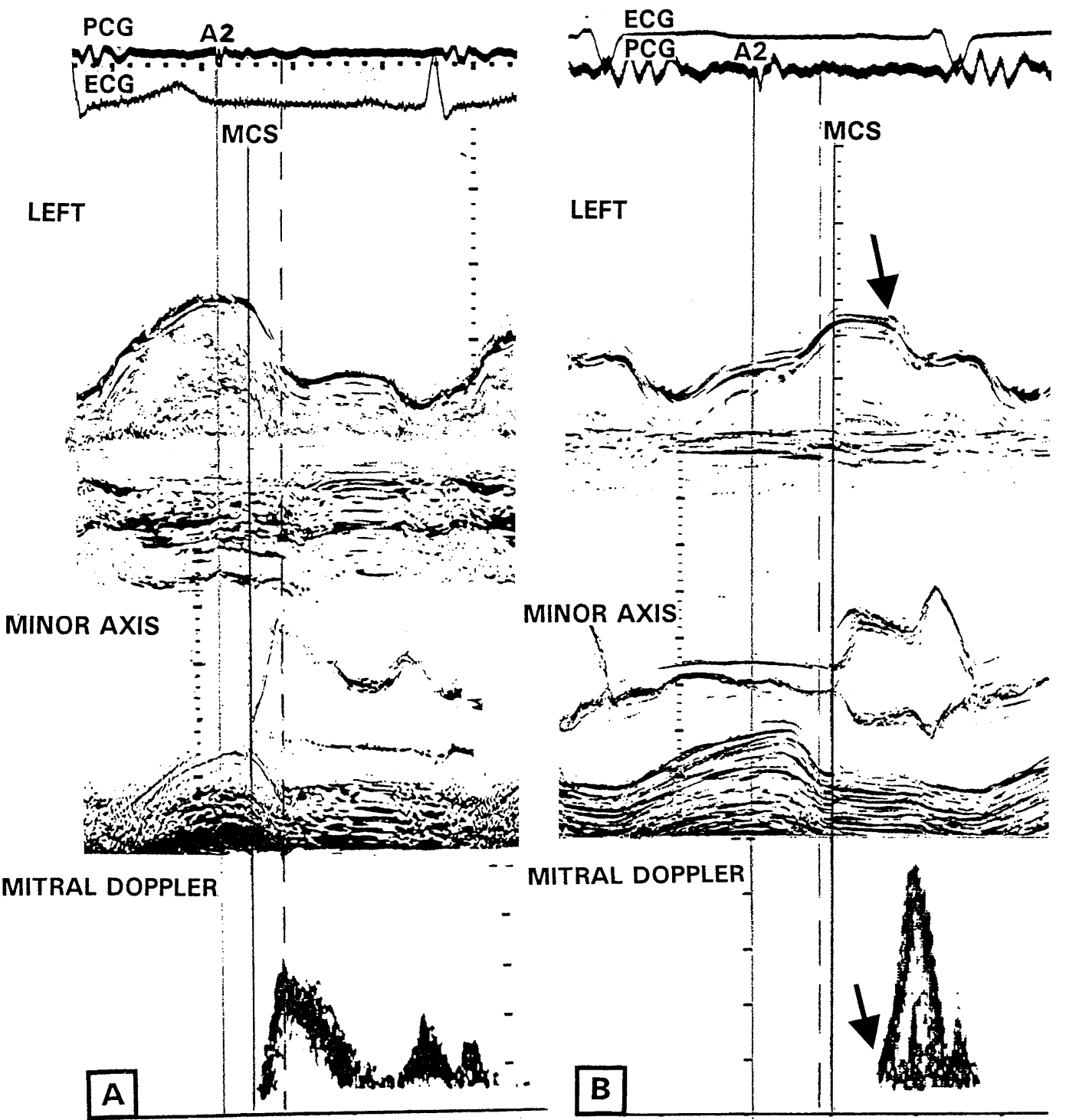


Table 3 Dimension change mean (SD) measurements between $A_{2}$ and mitral cusp separation in normal controls and patients in whom left ventricular early diastolic filling is absent

\begin{tabular}{|c|c|c|}
\hline Variables & $\begin{array}{l}\text { Normal controls } \\
(n=21)\end{array}$ & $\begin{array}{l}\text { Patients without left } \\
\text { ventricular early } \\
\text { diastolic filling } \\
(n=20)\end{array}$ \\
\hline $\begin{array}{l}\text { Minor axis } \\
\text { Extent of excursion (cm) } \\
\% \text { of excursion }\end{array}$ & $\begin{array}{l}-0.13(0.1) \\
-8.6(2.5)\end{array}$ & $\begin{array}{l}-0.35(0.3)^{\star \star} \\
-30(20)^{\star \star}\end{array}$ \\
\hline $\begin{array}{l}\text { Long axis } \\
\text { Extent of abnormal shortening (cm) } \\
\text { Left } \\
\text { Septum } \\
\text { Right }\end{array}$ & $\begin{array}{l}-0.16(0.1) \\
-0.1(0.06) \\
-0.3(0.1)\end{array}$ & $\begin{array}{l}+0.25(0.2)^{\star \star} \\
+0.24(0.2)^{\star \star} \\
-0.37(0.2)\end{array}$ \\
\hline $\begin{array}{l}\text { Dimension change (\%) } \\
\text { Left } \\
\text { Septum } \\
\text { Right } \\
\text { Peak rate of abnormal }\end{array}$ & $\begin{array}{l}-10(2 \cdot 5) \\
-6 \cdot 6(0 \cdot 3) \\
-11(2)\end{array}$ & $\begin{array}{l}+25(12)^{\star \star} \\
+50(30)^{\star \star} \\
-20(10)^{\star \star}\end{array}$ \\
\hline $\begin{array}{l}\quad \text { shortening }(\mathrm{cm} / \mathrm{s}) \\
\text { Left } \\
\text { Septum } \\
\text { Right }\end{array}$ & $\begin{array}{l}-2.4(2.0) \\
-0.9(1.9) \\
-5(2 \cdot 0)\end{array}$ & $\begin{array}{l}+0.4(3 \cdot 0)^{\star \star} \\
+3 \cdot 1(2 \cdot 3)^{\star \star} \\
-3 \cdot 1(4 \cdot 5)\end{array}$ \\
\hline
\end{tabular}

$\star \star \mathrm{P}<0.001 v$ normal

$\mathrm{A}_{2}$, aortic valve closure; + ve sign represents shortening; -ve sign represents lengthening.

Table 4 Comparison of early diastolic long axis function mean (SD) measurements between normal controls and patients in whom left ventricular early diastolic filling is absent

\begin{tabular}{|c|c|c|}
\hline Variables & $\begin{array}{l}\text { Normal controls } \\
(n=21)\end{array}$ & $\begin{array}{l}\text { Patients without left } \\
\text { ventricular early } \\
\text { diastolic filling } \\
(n=20)\end{array}$ \\
\hline $\begin{array}{l}\mathrm{A}_{2} \text { to onset of lengthening (ms) } \\
\text { Left } \\
\text { Septum } \\
\text { Right }\end{array}$ & $\begin{array}{l}58(11) \\
60(9) \\
40(5)\end{array}$ & $\begin{array}{c}190(60)^{\star \star} \\
200(35)^{\star \star} \\
75(60)^{\star}\end{array}$ \\
\hline $\begin{array}{l}\text { Peak lengthening rate }(\mathrm{cm} / \mathrm{s}) \\
\text { Left } \\
\text { Septum } \\
\text { Right }\end{array}$ & $\begin{array}{l}10(2 \cdot 5) \\
8 \cdot 5(2) \\
10(2)\end{array}$ & $\begin{array}{r}2 \cdot 2(4 \cdot 6)^{\star \star} \\
-0.2(2 \cdot 8)^{\star \star} \\
6.0(4 \cdot 5)^{\star \star}\end{array}$ \\
\hline
\end{tabular}

Table 5 Comparison of late diastolic long axis function mean (SD) measurements between normal controls and patients in whom left ventricular early diastolic filling is absent

\begin{tabular}{lll}
\hline & $\begin{array}{l}\text { Normal controls } \\
(n=21)\end{array}$ & $\begin{array}{l}\text { Patients without left } \\
\text { ventricular early } \\
\text { diastolic filling } \\
(n=20)\end{array}$ \\
Variables & $0 \cdot 4(0 \cdot 1)$ & $0 \cdot 7(0 \cdot 2)^{\star}$ \\
\hline Lengthening during atrial systole (cm) & $0 \cdot 5(0 \cdot 2$ & $0 \cdot 6(0 \cdot 1)^{\star}$ \\
$\quad$ Left & $0 \cdot 8(0 \cdot 2)$ & $1 \cdot 2(0 \cdot 5)^{\star}$ \\
Septum & & $67(17)^{\star \star}$ \\
Right & $29(6)$ & $77(13)^{\star \star}$ \\
\% lengthening during atrial systole & $33(8)$ & $60(18)^{\star \star}$ \\
$\quad$ Left & $33(5)$ & $6 \cdot 6(2 \cdot 9)$ \\
Septum & $6 \cdot 13(2 \cdot 2)^{\star}$ \\
Right & $4 \cdot 8(0 \cdot 8)$ & $8 \cdot 8(2 \cdot 4)$ \\
Peak rate of lengthening during atrial systole $(\mathrm{cm} / \mathrm{s})$ & \\
$\quad$ Left & $8 \cdot 0(1 \cdot 0)$ & \\
Septum & &
\end{tabular}

Table 6 Interrelation between minor and long axes, and mitral flow Doppler in normal controls and patients in whom left ventricular early diastolic filling is absent. Results are mean (SD)

\begin{tabular}{|c|c|c|}
\hline Variables & $\begin{array}{l}\text { Normal controls } \\
(n=21)\end{array}$ & $\begin{array}{l}\text { Patients without left } \\
\text { ventricular early } \\
\text { diastolic filling } \\
(n=20)\end{array}$ \\
\hline $\begin{array}{l}\text { Minor axis } \\
\mathrm{A}_{2} \text { to peak rate of lengthening (ms) } \\
\mathrm{A}_{2} \text { to end of posterior wall lengthening (ms) } \\
\mathrm{A}_{2} \text { to mitral cusp separation (ms) }\end{array}$ & $\begin{array}{r}95(15) \\
130(20) \\
60(10)\end{array}$ & $\begin{array}{r}75(20)^{\star} \\
95(30)^{\star \star} \\
115(30)^{\star \star}\end{array}$ \\
\hline $\begin{array}{l}\text { Long axis } \\
\mathrm{A}_{2} \text { to peak shortening (ms) } \\
\text { Left } \\
\text { Septum }\end{array}$ & $\begin{array}{l}-20(5) \\
-10(5)\end{array}$ & $\begin{array}{l}107(32)^{\star \star} \\
115(23)^{\star \star}\end{array}$ \\
\hline $\begin{array}{l}\mathrm{A}_{2} \text { to onset of lengthening (ms) } \\
\text { Left } \\
\text { Septum } \\
\text { Cusp separation to onset of flow (ms) }\end{array}$ & $\begin{array}{l}58(11) \\
60(9) \\
25(10)\end{array}$ & $\begin{array}{l}190(60)^{\star \star} \\
200(35)^{\star \star} \\
285(25)^{\star \star}\end{array}$ \\
\hline
\end{tabular}

6). Long axis lengthening starts $60 \mathrm{~ms}$ after $\mathrm{A}_{2}$; it coincides with mitral cusp separation and is followed after $20 \mathrm{~ms}$ by onset of the $E$ wave. Posterior wall thinning in patients in whom left ventricular early diastolic filling was absent ended $35 \mathrm{~ms}$ earlier than in the controls, while the long axis continued to shorten for $115 \mathrm{~ms}$ after $\mathrm{A}_{2}$ (fig 3). The time of minimum long axis length coincided with that of mitral cusp separation though transmitral flow was undetectable until $85 \mathrm{~ms}$ later. The long axis remained abnormally shortened until the onset of atrial systole which was when transmitral flow finally began.

\section{Discussion}

If blood does not enter the left ventricle during early diastole, one might expect its dimensions to remain unchanged. As the mitral valve orifice was self-evidently not obstructed in our patients, the primary disturbance was likely to have been one of ventricular relaxation. Ventricular pressure would thus be higher than pressure in the atrium until middiastole, and the mitral valve would remain closed until the onset of forward flow. Disturbances of relaxation are usually quantified from the high fidelity left ventricular pressure pulse, which allows a reduced relaxation rate, a prolonged time constant of pressure fall, to be distinguished from the entity of incomplete relaxation, in which the equilibrium value is raised. ${ }^{7}$ Any method based on the pressure pulse must assume that myocardial relaxation is uniform.

We believe that our interest in patients with no detectable transmitral $\mathrm{E}$ wave is justified by the finding that these apparently reasonable predictions and assumptions about diastolic function were incorrect. There were major changes in left ventricular dimensions at a time when its volume was effectively constant. The minor axis increased, and the long axis continued to shorten. Clearly, therefore, the relaxation process was grossly incoordinate, so that it would have been inappropriate to have quantified it from a single exponential superimposed on the ventricular pressure pulse. Far from remaining closed, the mitral valve cusps separated $85 \mathrm{~ms}$ before the onset of detectable transmitral flow, and despite this we were unable to detect any retrograde flow. The wide discrepancies between what could reasonably have been predicted and what was observed suggest that conventional ideas give only an incomplete understanding of early diastole, particularly as applied to the patients whom we studied.

Clinical data did not help to identify the underlying abnormality. The patients were all elderly. The majority had heart disease and disturbances of activation were common. The relative height of the mitral $\mathrm{E}$ wave with respect to the A wave tends to fall with age, ${ }^{8}$ but it is most uncommon for it to disappear. Conduction disturbances were inconsistent. Heart rate was not significantly different between patients in whom left ventricular early diastolic filling was absent and normal 
controls. Heart disease, when present, was caused by either coronary artery disease or left ventricular hypertrophy, both of which modify early diastole, ${ }^{6910}$ though not to the extent seen in our patients. Although all our patients were receiving diuretic agents, and all but two taking an ACE inhibitor, we believe that this high incidence reflects the frequency with which these drugs are now prescribed to patients with heart disease. We have no evidence, therefore, to attribute any specific aetiological role to them

Left ventricular long axis function was very abnormal in all our patients. It lengthened during isovolumic contraction and started to shorten late. Its diastolic behaviour was even more disturbed. It continued to shorten after $\mathrm{A}_{2}$, reaching its peak $115 \mathrm{~ms}$ later than normal. It did lengthen after this period, but only at a greatly reduced rate until atrial systole and the onset of forward flow. The minor axis was also abnormal. Minimum cavity dimension coincided with peak posterior wall thickness both of which occurred early, so that the dimension increased during isovolumic relaxation at the same time as the long axis was shortening. The mitral valve cusps separated $115 \mathrm{~ms}$ after $\mathrm{A}_{2}$; in individual patients this was later than the end of rapid posterior left ventricular wall thinning or transverse dimension increase, but consistently coincided with peak long axis shortening. There was then a further interval of $85 \mathrm{~ms}$, when the mitral valve was open and even showed "mid-diastolic closure" before any forward flow could be detected (fig 1). During this time, the minor axis remained constant and the long axis tended to lengthen. Finally, ventricular filling coincided with atrial systole and an abrupt increase in long axis, and again with little change in either transverse axis or wall thickness.

Unexpected as these findings are, they are perhaps less abnormal than might appear at first sight. Thinning of the posterior wall and increase in the transverse dimension both precede the start of the $\mathrm{E}$ wave by $50 \mathrm{~ms}$ in normal children, a finding that we have previously ascribed to left ventricular restoring forces. ${ }^{11}$ Similarly, mitral valve cusp separation normally precedes the start of the Doppler E wave by $25 \mathrm{~ms}$ and is synchronous with the onset of long axis lengthening. ${ }^{6}$ This latter relation was still present in our patients, though both were greatly delayed. Thus, the striking dissociation of wall motion, mitral cusp separation, and blood flow did not seem to represent the appearance of totally new abnormalities; rather it was an accentuation of asynchrony already present in normal individuals. ${ }^{12}$

On this basis, we suggest that delayed and prolonged long axis shortening is the primary disturbance in our patients. This may have been the result of activation disturbance, ${ }^{13}$ subendocardial ischaemia, ${ }^{9}$ or other causes still to be identified, either alone or in combination. This prolonged shortening interacts with rapid thinning of the posterior left ventricular wall, a process that we have already suggested to be autonomous and a major site of restoring forces. ${ }^{14}$ Energy normally coupled to filling is thus dissipated as a change in cavity shape. Reciprocal inward and outward wall motion during isovolumic relaxation in different parts of the ventricle has previously been demonstrated in detail by contrast angiography. ${ }^{15}$ The alternative explanation of the change in cavity shape, that free wall thinning is abnormally forceful and causes passive long axis shortening, is difficult to sustain. It is not clear why wall thinning should be abnormally forceful, nor if it was so, how passive long axis shortening could occur without increased rather than absent early diastolic mitral inflow, particularly if the mitral cusps are separated. Once it is accepted that restoring forces are dissipated, then the absence of forward mitral flow becomes readily explicable. The associated absence of backward flow presumably reflects the condition of atrioventricular equilibrium, which is disturbed only by the onset of atrial systole. This hypothesis might be further investigated by manipulating atrioventricular delay by pacing, but we did not have this opportunity. The exact cause of mitral cusp separation in the absence of flow remains unclear. Perhaps the sudden cessation of long axis shortening, or the onset of lengthening may generate the necessary vortices to cause the cusps to separate. Alternatively the similarity in subendocardial and papillary muscle structure might be invoked; a sudden reduction in papillary muscle tension may allow the mitral valve to open.

Our study has obvious technical limitations. Doppler cannot detect stationary blood, and therefore cannot exclude blood flow at very low velocity. We used a low frequency wall filter $(250 \mathrm{~Hz})$, a frequency chosen as being only just above that of noise level. We were thus not able to exclude early diastolic flow altogether, but to define an upper limit of about $10 \mathrm{~cm} / \mathrm{s}$, or less than $10 \%$ that in atrial systole. We doubt that the difference between this level and zero flow affects our conclusions to any material extent. We would note that there is no example of physiologically significant flow within the heart being undetectable by pulsed Doppler because its velocity is low. Theoretically, zero flow could be confirmed or excluded by contrast $M$ mode echocardiography, but unfortunately left sided contrast agents were not available to us. We did use $M$ mode echocardiography to define mitral cusp separation. This technique cannot examine the whole valve, so the possibility arises that our results were not representative. Again, we do not feel that this materially alters our conclusions. Once cusp separation has occurred in any part of the valve, it is effectively open. Opening velocities were so high, that we do not believe that major differences could exist between different parts of the cusps. If they were to do so, this would have the effect of slightly reducing the interval from $\mathrm{A}_{2}$ to apparent cusp separation, and correspondingly increasing that from cusp separation to the onset of flow. 
We have previously suggested that the Doppler transmitral $\mathrm{E} / \mathrm{A}$ ratio is largely determined by the length of the isovolumic period and the degree of incoordinate wall motion during it, and only to a minor extent by the properties of the left ventricle during filling. ${ }^{16}$ The patients described here had an unusual degree of incoordination during isovolumic relaxation time, and the interval from $\mathrm{A}_{2}$ to mitral cusp separation was greatly prolonged. On the basis of previous studies, therefore, a major decrease in early diastolic flow would have been predicted; observation shows it to have been effectively absent. Our results thus further confirm the validity of this unorthodox approach to the study of left ventricular diastolic properties. Disturbances of isovolumic relaxation usually arise earlier in the cardiac cycle, from either abnormal activation $^{13}$ or local depression of systolic function. ${ }^{17}$ Both were present among our patients. Our results also illustrate the value of considering long axis function rather than attempting to describe diastolic function in terms of pressure and flow alone. Without this extra information the sequence of events that we have described would have been very difficult to interpret. Finally, it is becoming clear that disturbances of diastolic function form a major part of the syndrome of heart failure. If they are to be successfully treated, it is to the primary cause and not the secondary effects that effort should be directed. The results described here may represent a step in this direction.

1 Ishida Y, Meisner JS, Tsujioka K, Gallo JI, Yoran C, Frater RMW, et al. Left ventricular filling dynamics: influence of left ventricular relaxation and left atrial pressure. Circulation 1986;74:187-96.
2 Nikolic S, Yellin EL, Tramura K, Vetter H, Tamura T, Meisner J, et al. Passive properties of canine left ventricle: diastolic stiffness and restoring forces. Circ Res cle: diastolic stiffics

3 Paulus W, Rousseau MF, Vantrimpont P, Stockbroeckx J, Couck B. Diastolic function of the non-filling human left ventricle. Circulation 1992;84(suppl):II-43

$4 \mathrm{Ng} \mathrm{KSK}$, Gibson DG. Relation of filling pattern to diastolic function in severe left ventricular disease. Br Heart $\mathcal{f}$ 1990;63:209-14.

5 Upton MT, Gibson DG. The study of left ventricular function from digitized echocardiograms. Prog Cardiovasc Dis 1978;20:359-84.

6 Henein MY, Priestley K, Davarashvili T, Buller N, Gibson DG. Early changes in left ventricular subendocardial function after successful coronary angioplasty. Br Heart f 1993;69:501-6.

7 Weisfeldt ML, Weiss JL, Frederiksen JT, Yin FCP. Quantification of incomplete left ventricular relaxation: relationship to the time constant for isovolumic pressure fall. Eur Heart f 1980;1 (suppl A):119-29.

8 Bryg RJ, Williams GA, Labovitz AJ. Effect of aging on left ventricular diastolic filling in normal subjects. $A m \mathcal{F}$ ventricular diastolic fillin

9 Upton MT, Gibson DG, Brown DJ. Echocardiographic assessment of abnormal left ventricular relaxation in man. Br Heart f 1976;38:1001-9.

10 Gibson DG, Traill TA, Hall RJC, Brown DJ. Echocardiographic features of secondary left ventricular hypertrophy. Br Heart $\mathcal{f} 1979 ; 41: 54-9$.

11 Park CH, Chow WH, Gibson DG. Phase differences between left ventricular wall motion and transmitral flow in man: evidence for involvement of ventricular restoring forces in normal rapid filling. Int $\mathcal{f}$ Cardiol 1989;24: 347-54.

12 Lee CH, Vancheri F, Josen MS, Gibson DG. Discrepancies in the measurement of isovolumic relaxation time: a study comparing $M$ mode and Doppler
echocardiography. Br Heart $\mathcal{f} 1990 ; 64: 214-8$.

13 Xiao HB, Gibson DG. Absent septal q wave: a marker of the effects of abnormal activation pattern on the left venthe effects of abnormal activation pattern on the left ve
tricular diastolic function. Br Heart $₹$ 1994;72:45-51.

14 Traill TA, Gibson DG. Left ventricular relaxation and filling: study by echocardiography. In: Yu PN, Goodwin F, eds. Progress in cardiology. Philadelphia: Lee \& Febiger, 1979;8:39-72

15 Gibson DG, Prewitt TA, Brown DJ. Analysis of left ventricular wall movement during isovolumic relaxation and its relation to coronary artery disease. $\mathrm{Br}$ Heart $\mathcal{f}$ 1976;38:1010-9.

16 Brecker SJD, Lee CH, Gibson DG. Relation of left ventricular isovolumic relaxation time and incoordination to transmitral Doppler filling patterns. $B r$ Heart $\mathcal{f} 1992$; 68:567-73.

17 Gibson DG, Doran JH, Traill TA, Brown DJ. Abnormal left ventricular wall movement during early systole in patients with angina pectoris. $B r$ Heart $\mathcal{F} 1978 ; 40$ : 758-66. 